\title{
Article \\ Nonlinear Effect and MAI Impact on SAC-OCDMA System Based on 2D Multi-Diagonal Code and Laser Array
}

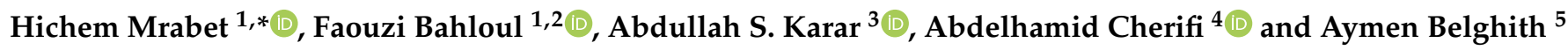 \\ 1 SERCOM Laboratory, Tunisia Polytechnic School, University of Carthage, EPT, B.P. 743, Tunis 2078, Tunisia; \\ faouzi.bahloul@enit.rnu.tn \\ 2 National Engineering School of Tunis, University of Tunis El Manar, B.P. 37, Tunis 1002, Tunisia \\ 3 College of Engineering and Technology, American University of the Middle East, Kuwait; \\ abdullah.Karar@aum.edu.kw \\ 4 Technology of Communication Laboratory (LTC), University of Tahar Moula, Saida 28014, Algeria; \\ cherifi.abdelhamid@gmail.com \\ 5 College of Computing and Informatics, Department of Computer Science, Saudi Electronic University, \\ Riyadh 11673, Saudi Arabia; a.belghith@seu.edu.sa \\ * Correspondence: hichem.mrabet@gmail.com; Tel.: +216-71-774-611
}

Citation: Mrabet, H.; Bahloul, F.; Karar, A.S.; Cherifi, A.; Belghith, A. Nonlinear Effect and MAI Impact on SAC-OCDMA System Based on 2D Multi-Diagonal Code and Laser Array. Appl. Sci. 2021, 11, 8528. https://doi.org/10.3390/app 11188528

Academic Editor: John Xiupu Zhang

Received: 28 July 2021

Accepted: 8 September 2021

Published: 15 September 2021

Publisher's Note: MDPI stays neutral with regard to jurisdictional claims in published maps and institutional affiliations.

Copyright: (C) 2021 by the authors Licensee MDPI, Basel, Switzerland. This article is an open access article distributed under the terms and conditions of the Creative Commons Attribution (CC BY) license (https:/ / creativecommons.org/licenses/by/ $4.0 /)$.
Abstract: A new architecture for Spectral Amplitude Coding Optical Code Division Multiple Access (SAC-OCDMA) system based on two Dimensional Multi Diagonal (2D-MD) codes named 2D-MD SAC-OCDMA and utilizing a laser optical source is proposed for Long-Reach Passive Optical Network (LR-PON). In this work, a computer simulator tool is used, for the first time, as a SACOCDMA simulation set-up utilizing the unique combination of a coherent laser array and 2D-MD codes. In addition, the system performance is addressed numerically by taking into account Multiple Access Interference (MAI), optical coherent source noise, first, second and third order fiber dispersion, nonlinear effects and photo-detector noise. Simulation results indicate that for a single user (i.e., without considering MAI), the system can operate at a maximum bit rate of $55 \mathrm{~Gb} / \mathrm{s}$ over $250 \mathrm{~km}$ of Single Mode Fiber (SMF), with a Bit Error Rate (BER) below $10^{-9}$ (Q-limit $=15.5 \mathrm{~dB}$ ), when only first order fiber dispersion is considered. However, including the effects of second and third order fiber dispersion as frequency domain parameters, results in a reduction of the maximum bit rate to $40 \mathrm{~Gb} / \mathrm{s}$, while maintaining a Q-factor above the Q-limit under the same transmission distance. Furthermore, we demonstrate that the proposed architecture extends the SMF transmission reach up to $600 \mathrm{~km}$ and $480 \mathrm{~km}$, when considering linear and nonlinear effects, respectively. Finally, we show that our proposed 2D-MD SAC-OCDMA system outperforms existing solutions presented in the literature for LR-PON configuration, in terms of both aggregate bit rate and transmission reach.

Keywords: LR-PON; SAC-OCDMA; MAI; SMF; nonlinearity; Kerr effect; Raman effect; laser array; security

\section{Introduction}

Based on the nature of the optical source (i.e., coherent versus incoherent), the detection configuration scheme (i.e., coherent versus incoherent) and coding techniques (i.e., time/wavelength or amplitude/phase), optical code division multiplexing access (OCDMA) systems are either coherent or incoherent [1]. On the one hand, CDMA coherent systems use bipolar codes $\{-1,1\}$ such as Maximum Length (ML) sequences and Walsh codes which are employed in wireless CDMA systems. On the other hand, CDMA incoherent systems employ unipolar codes $\{0,1\}$ such as optical orthogonal codes (OOC) and prime codes [2]. Additionally, OCDMA systems are divided into three families; direct sequence OCDMA (DS-OCDMA) [3], time hopping OCDMA (TH-OCDMA) [4] and frequency hopping OCDMA (FH-OCDMA) [5]. OCDMA systems are also classified into two categories: synchronous and asynchronous [6]. Synchronous systems provide a high user capacity that 
makes them more complex, whereas asynchronous systems are less complex [7]. Moreover, OCDMA synchronous system provides a secure data transmission [8].

In literature, several works dealing with synchronous OCDMA systems are investigated based on one dimensional (1D) code and satisfying the zero cross-correlation (ZCC) feature. The ZCC feature is promising by improving system cardinality, while limiting interference $[9,10]$. However, a specific coding family based on two-dimensional (2D) code namely multi-diagonal code (2D-MD) for spectral amplitude coding OCDMA (SACOCDMA), offers additional improvement to the system cardinality without the constraint of increasing the length of the 1D code [11]. Whereas, the previous 2D-MD proposed systems, using incoherent source and operating at low bit rates equal to $622 \mathrm{Mb} / \mathrm{s}, 1 \mathrm{~Gb} / \mathrm{s}$ and $2.5 \mathrm{~Gb} / \mathrm{s}$, are studied in [12-14], respectively. Unfortunately, these bit rates do not satisfy the required user needs for different emergent applications and for the increasing demand in access network. In [14], authors developed the SNR expression of SAC-OCDMA system based on 2D-MD code while using LED source. However, in this work, we investigate a numerical analysis and a feasibility demonstration via simulation for SAC-OCDMA system utilizing the unique combination of a 2D-MD code and coherent light source. Laser sources are characterized by a narrowband spectral width and produce less chromatic dispersion compared to LED sources. Moreover, laser sources allow various types of modulation schemes, such as Frequency Shift Keying (FSK), Phase Shift Keying (PSK) and Quadrature Phase Shift Keying (QPSK) for high distance and data rate. Additionally, LED source is known as a cost-effective device. For instance, Sharma and al. [15] proposed a simulation model for SAC-OCDMA system based on two-dimensional Balanced Incomplete Block Design (2D-BIBD) codes for six users operating at $1 \mathrm{~Gb} / \mathrm{s}$ and LED source. Additionally, authors in [16] demonstrated the feasibility of two-dimensional permutation vector codes (2D-PV) based on LED source and providing a BER less than $10^{-9}$ for eight users operating at $2 \mathrm{~Gb} / \mathrm{s}$. However, due to the non-coherency of its broadband source, the Phase-Induced Intensity Noise (PIIN) is a dominant factor which limits the system performance and the maximum achievable bit rate [17]. Furthermore, laser can allow other optimizations such as dispersion tolerance for high-speed transmission links and can be employed for high data rates up to $10 \mathrm{~Gb} / \mathrm{s}$ [18]. The choice of the LED against laser source depends on the application, target performance and reliability requirement. For instance, LED is used mainly in fiber to the home (FTTH) and Local Area Network (LAN) [14], whereas laser source is employed in long-haul applications such as Metropolitan Area Network (MAN) [18]. In the state-of-the-art, many authors consider coherent source for SAC-OCDMA systems for various applications such as Passive Optical Network (PON) [18-21], Free Space Optical (FSO) [22] and wireless optical networks [23].

This paper aims to employ coherent source in a PON context to improve the SACOCDMA system performance in terms of allowed user bit rate and maximum system reach. A novel architecture based on 2D-MD SAC-OCDMA codes for LR-PON is proposed with a coherent optical source, an external Mach-Zehnder modulator, spectral/temporal coding and spectral direct detection (SDD). In addition, we investigate the system performance in terms of the maximum achievable bit rate, Q-factor and eye diagram analysis using a computer simulator tool. Firstly, we study the feasibility of a SAC-OCDMA system based on 2D-MD in LR-PON. Secondly, we determine the maximum reachability of the system in terms of fiber length. Finally, we investigate the impact of linear effects (i.e., fiber loss, group velocity dispersion and differential group delay) and non-linear effects (i.e., Kerr effect, self-phase modulation and stimulated Raman scattering) of the optical channel on the system performance when increasing the bit rate. Recall that the bit rate is correlated to the nonlinear effects in optical communication systems. Therefore, when the bit rate increases, the nonlinear effects caused by the optical channel will increase as well leading to a degradation of the system performance [24]. On the one hand, in this paper we focus on determining the maximum bit rate that results in a Q-factor higher than the limit corresponding to a bit error rate (BER) of $10^{-9}$, when nonlinear effects due to optical channel are considered. On the other hand, a simulation setup is proposed 
to study the impact of Multiple Access Interference (MAI) and nonlinear effects while increasing the number of network subscribers. For a single user, we demonstrate that the proposed system can reach up to $55 \mathrm{~Gb} / \mathrm{s}$ and $40 \mathrm{~Gb} / \mathrm{s}$ when first, and second (as well as third) order dispersion are considered as frequency parameters, respectively. In addition, the simulation setup shows four connected users operating at an aggregate bit rate of $20 \mathrm{~Gb} / \mathrm{s}$ over $50 \mathrm{~km}$ of single-mode fiber (SMF) link while considering linear and nonlinear effects. Furthermore, the nonlinear effects are considered by enabling the Kerr effect (i.e., $\gamma)$ in the simulator, the self-phase modulation (SPM) and the stimulated Raman scattering (SRS) at a bit rate of $5 \mathrm{~Gb} / \mathrm{s}$ per user. To the best of our knowledge, this is the first time to demonstrate the feasibility of a 2D-MD SAC-OCDMA system in LR-PON context by considering optical coherent source noise, group velocity dispersion (GVD), differential group delay (DGD), SPM, SRS effects and photo detector noise. The received electrical eye diagrams reveal an aggregate bit rate of $20 \mathrm{~Gb} / \mathrm{s}$ dispatched equally among four users over $50 \mathrm{~km}$ of SMF length that had never been reached before compared to similar systems in PON configuration.

This paper is organized as follows. Section 2 presents the system description for LR-PON. Section 3 deals with the SAC-OCDMA encoder and decoder model in which 2D-MD codes are exhibited. Section 4 discusses the system performance analysis in terms of SNR, BER and Q-Factor. Simulation results and discussion are investigated, in Section 5, as function of bit rate, optical channel nonlinear coefficient and fiber length. Finally, some conclusions are drawn in Section 6.

\section{System Architecture}

Figure 1 describes the architecture of the proposed 2D-MD SAC-OCDMA system for LR-PON applications with four users. The user data is modulated with a Mach-Zehnder modulator (MZM). Then, the modulated user signal is multiplied by 2D-MD OCDMA code that is generated by the OCDMA encoder. The channel is represented through $50 \mathrm{~km}$ of SMF length followed by an optical amplifier (i.e., Erbium-Doped Fiber Amplifier (EDFA) with a gain equal to $10 \mathrm{~dB}$ ), a Dispersion Compensating Fiber (DCF) and a second optical amplifier with the same gain. The reachability of the system can be extended up to $600 \mathrm{~km}$ using a block loops equal to 12 and a SMF length of $50 \mathrm{~km}$. A DCF, with length equal to $10 \mathrm{~km}$ and a negative chromatic dispersion coefficient (i.e., $D_{\mathrm{c}}=-80 \mathrm{ps} / \mathrm{nm} / \mathrm{km}$ ), is used to fully compensate the chromatic dispersion caused by the SMF. At the reception side, a splitter is used to share the optical composite signal among all users. Then, a SAC-OCDMA decoder based on 2D-MD OCDMA code is used to separate the target user signal from other users' signals. Finally, a photo-detector PIN is employed to recover the user transmitted data.

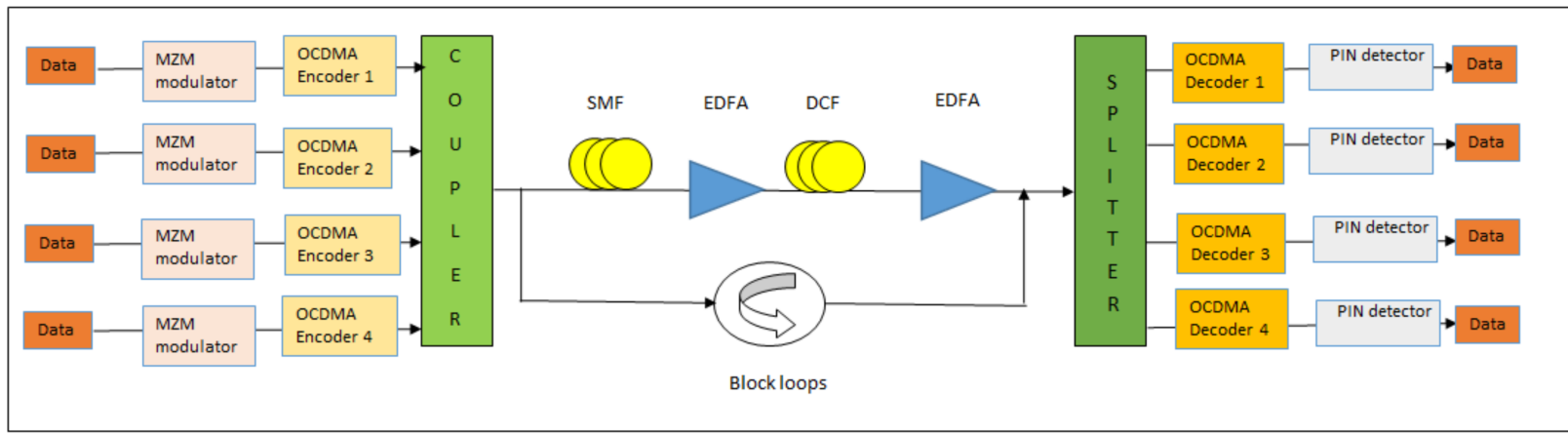

Figure 1. Proposed 2D-MD SAC-OCDMA system architecture (MZM: Mach-Zehnder modulator, EDFA: Erbium-doped fiber amplifier, SMF: Single mode Fiber, DCF: Dispersion compensating fiber). 


\section{SAC-OCDMA System Description}

The 2D-MD code is designed using two 1D-MD code sequences, where the code length $L$ is defined by [14]:

$$
L=w \cdot K
$$

where $w$ is the code weight and $K$ is the number of users.

Due to the ZCC proprieties (i.e., cross correlation between two adjacent codes is equal to zero), MAI effects are totally canceled for 1D-MD code. Therefore, 1D-MD code can be designed using the following steps [25]:

Step 1: Depending on several diagonal matrices by choosing the corresponding weight and user number " $w$ " and " $K$ ", both " $m$ " and " $n$ " can be configured where $m \in[1, K]$ and $n \in[1, w]$ refer to the rows number and the diagonal matrices number in each matrix, respectively.

Step 2: Each diagonal matrix in MD code can be expressed by:

$$
\begin{aligned}
& S_{m, n}=\left\{\begin{array}{lrr}
K+1-m & \text { if } & n=\text { even number } \\
m & \text { if } & n=\text { odd number }
\end{array}\right. \\
& S_{m, 1}=\left[\begin{array}{c}
1 \\
2 \\
3 \\
\vdots \\
K
\end{array}\right], S_{m, 2}=\left[\begin{array}{c}
K \\
\vdots \\
3 \\
2 \\
1
\end{array}\right], \ldots \ldots, S_{m, w}=\left[\begin{array}{c}
1 \\
2 \\
3 \\
\vdots \\
K
\end{array}\right]
\end{aligned}
$$

Each one of the above elements refers to column in $I_{m, n}$ square matrices with $K \times K$ order.

$$
I_{m, 1}=\left[S_{m, 1}\right]_{K \times K}, I_{m, 2}=\left[S_{m, 2}\right]_{K \times K}, \ldots \ldots, I_{m, w}=\left[S_{m, w}\right]_{K \times K}
$$

$I_{m, n}$ can be expressed as:

$I_{m, 1}=\left[\begin{array}{ccc}1 & 0 & \cdots \\ 0 & 1 & \cdots \\ & \vdots & \\ 0 & 0 & \cdots\end{array}\right.$

$\left.\begin{array}{cc}0 & 0 \\ 0 & 0 \\ & \vdots \\ 0 & 1\end{array}\right] I_{m, 2}=\left[\begin{array}{ccccc}0 & 0 & \ldots & 0 & 1 \\ 0 & 0 & & 1 & 0 \\ \vdots & \ddots & \vdots \\ 1 & 0 & \cdots & 0 & 0\end{array}\right], \ldots \ldots, I_{m, w}=\left[\begin{array}{ccccc}1 & 0 & \ldots & 0 & 0 \\ 0 & 1 & & 0 & 0 \\ \vdots & \ddots & \vdots & \\ 0 & 0 & \cdots & 0 & 1\end{array}\right]$

Step 3: Combining different $I_{m, n}$ matrices conducts to obtain 1D-MD matrix as follows:

$$
M D=\left[\begin{array}{llllllll} 
& \vdots & & & & & \vdots \\
I_{m, 1} & \vdots & I_{m, 2} & \vdots & \ldots & \ldots & \vdots & I_{m, w}
\end{array}\right]_{K \times L}
$$

Table 1 represents an example of $1 \mathrm{D}-\mathrm{MD}$ code for $w=3, K=4$ and $\mathrm{L}=12$ [11].

Table 1. 1D-MD code sequence for $w=3, K=4$ and $L=12$.

\begin{tabular}{ccccccccccccc}
\hline $\mathbf{m}$ & \multicolumn{10}{c}{ m-Sequence } \\
\hline 1 & 1 & 0 & 0 & 0 & 0 & 0 & 0 & 1 & 1 & 0 & 0 & 0 \\
2 & 0 & 1 & 0 & 0 & 0 & 0 & 1 & 0 & 0 & 1 & 0 & 0 \\
3 & 0 & 0 & 1 & 0 & 0 & 1 & 0 & 0 & 0 & 0 & 1 & 0 \\
4 & 0 & 0 & 0 & 1 & 1 & 0 & 0 & 0 & 0 & 0 & 0 & 1 \\
\hline
\end{tabular}

In SAC-OCDMA system, a code is described with 5-tuplet $\left(K, L, w, \lambda_{a}, \lambda_{c}\right)$ where $K, L, w, \lambda_{\mathrm{a}}$ and $\lambda_{\mathrm{c}}$ are defined as the number of simultaneous users, the code length, the code weight, the auto-correlation and the cross-correlation of the code. Table 1 exhibits the SAC-OCDMA 1D-MD codes description for $(K=4, L=12, w=3, \lambda c=0)$ while performing the time and wavelength spreading, respectively [14].

Table 2 presents an example of 2D-MD code time spreading description generated from two 1D-MD codes $X=$ [100110] and $Y=$ [011001] with $\left(w_{1}=3, k_{1}=2, w_{2}=3\right.$ and $\left.k_{2}=3\right)$. Where $w_{1}, w_{2}, k_{1}$ and $k_{2}$ represent $X$ and $Y$ codes weight and size. In addition, we define $M=w_{1} \cdot k_{1}$ and $P=k_{2} \cdot w_{2}$ as the code length of $\mathrm{X}$ and $\mathrm{Y}$ used to build the 2D-MD code. 
Table 2. 2D-MD code time spreading description.

\begin{tabular}{lllllllllllllll}
\hline & 1 & 0 & 0 & 1 & 1 & 0 & & 0 & 1 & 1 & 0 & 0 & 1 & \\
\hline 1 & 1 & 0 & 0 & 1 & 1 & 0 & & 0 & 1 & 1 & 0 & 0 & 1 \\
0 & 0 & 0 & 0 & 0 & 0 & 0 & & 0 & 0 & 0 & 0 & 0 & 0 \\
0 & 0 & 0 & 0 & 0 & 0 & 0 & & 0 & 0 & 0 & 0 & 0 & 0 \\
1 & 1 & 0 & 0 & 1 & 1 & 0 & & 0 & 1 & 1 & 0 & 0 & 1 \\
1 & 1 & 0 & 0 & 1 & 1 & 0 & & 0 & 1 & 1 & 0 & 0 & 1 \\
0 & 0 & 0 & 0 & 0 & 0 & 0 & & 0 & 0 & 0 & 0 & 0 & 0 & \\
\hline 0 & 0 & 0 & 0 & 0 & 0 & 0 & & 0 & 0 & 0 & 0 & 0 & 0 \\
1 & 1 & 0 & 0 & 1 & 1 & 0 & & 0 & 1 & 1 & 0 & 0 & 1 \\
1 & 1 & 0 & 0 & 1 & 1 & 0 & & 0 & 1 & 1 & 0 & 0 & 1 \\
0 & 0 & 0 & 0 & 0 & 0 & 0 & & 0 & 0 & 0 & 0 & 0 & 0 \\
0 & 0 & 0 & 0 & 0 & 0 & 0 & & 0 & 0 & 0 & 0 & 0 & 0 \\
1 & 1 & 0 & 0 & 1 & 1 & 0 & & 0 & 1 & 1 & 0 & 0 & 1 \\
\hline
\end{tabular}

Table 3 describes the 2D-MD spectral code. In this table, we show that:

- $\quad \lambda_{1}=1550 \mathrm{~nm}, \lambda_{8}=1555.6 \mathrm{~nm}$ and $\lambda_{9}=1556.4 \mathrm{~nm}$ are assigned to user 1 .

- $\quad \lambda_{2}=1550.8 \mathrm{~nm}, \lambda_{7}=1554.8 \mathrm{~nm}$ and $\lambda_{10}=1557.2 \mathrm{~nm}$ are assigned to user 2 .

- $\quad \lambda_{3}=1551.6 \mathrm{~nm}, \lambda_{6}=1554 \mathrm{~nm}$ and $\lambda_{11}=1558 \mathrm{~nm}$ are assigned to user 3 .

- $\quad \lambda_{4}=1552.4 \mathrm{~nm}, \lambda_{5}=1553.2 \mathrm{~nm}$ and $\lambda_{12}=1558.8 \mathrm{~nm}$ are assigned to user 4 .

Table 3. 2D-MD spectral code description.

\begin{tabular}{|c|c|c|c|c|c|c|c|c|c|c|c|c|}
\hline & $\lambda_{1}$ & $\lambda_{2}$ & $\lambda_{3}$ & $\lambda_{4}$ & $\lambda_{5}$ & $\lambda_{6}$ & $\lambda_{7}$ & $\lambda_{8}$ & $\lambda_{9}$ & $\lambda_{10}$ & $\lambda_{11}$ & $\lambda_{12}$ \\
\hline C1 & & & & & & & & & & & & \\
\hline $\mathrm{C} 2$ & & & & & & & & & & & & \\
\hline C3 & & & & & & & & & & & & \\
\hline C4 & & & & & & & & & & & & \\
\hline
\end{tabular}

Note that the 2D-MD codes are selected thanks to the ZCC propriety leading to limit the MAI. Recall that the MAI is considered as the most important OCDMA system performance limitation [14]. In fact, MAI is due to the overlap between the common chips of the user's code in time or spectral axis in the combined signal when it is transferred through the optical channel. According to Table 2 that describes the 2D-MD time spreading, the overlap chips are represented with red color. However, to reduce the MAI we suggested 12 wavelengths for the spectral spreading as depicted in Table 3 to serve four users. Furthermore, to minimize the overlap between the different wavelengths, we select a bandwidth equal to $0.8 \mathrm{~nm}$ between the 12 selected wavelengths. Figure 2a shows the SAC-OCDMA encoder used to generate the $2 \mathrm{D}-\mathrm{MD}$ codes in which a time delay (Delay $=1 /\left(\right.$ Bit rate $\left.\left.\times \frac{1}{4}\right)\right)$ is used for time spreading and wavelength division multiplexing (WDM) multiplexer is employed to assign different wavelength for different generated chip. On the other side, a Bessel optical filter followed by a time delay in the SAC-OCDMA decoder for user 1 is used to extract the user signature from the multiplexed received signal as depicted in Figure 2b. Moreover, Fibre Bragg Grating (FBG) and Arrayed Waveguide Grating (AWG) are demonstrated for spectral encoder/decoder that can be a potential solution for physical implementation very suitable in SAC-OCDMA systems. However, in our work only an Optical Tapped-Delay Line (OTDL) is required for the corresponding proposed time delay components for physical implementation since the spectral component of the 2D-MD codes are provided by the $\mathrm{CW}$ laser array. 


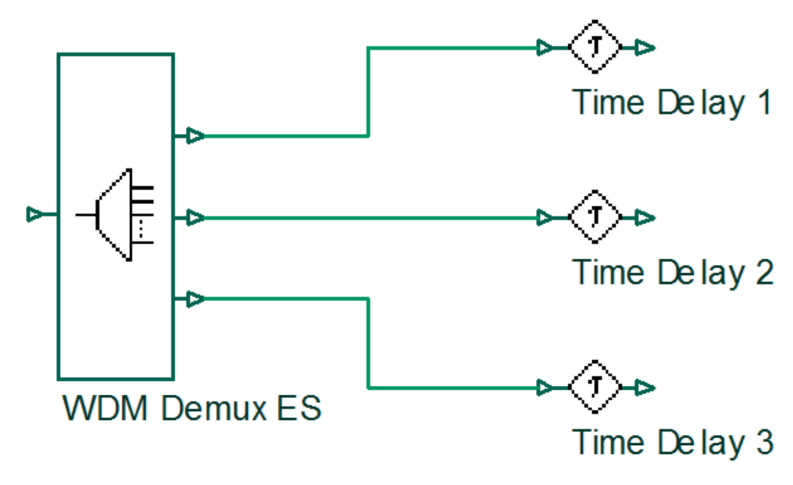

(a)

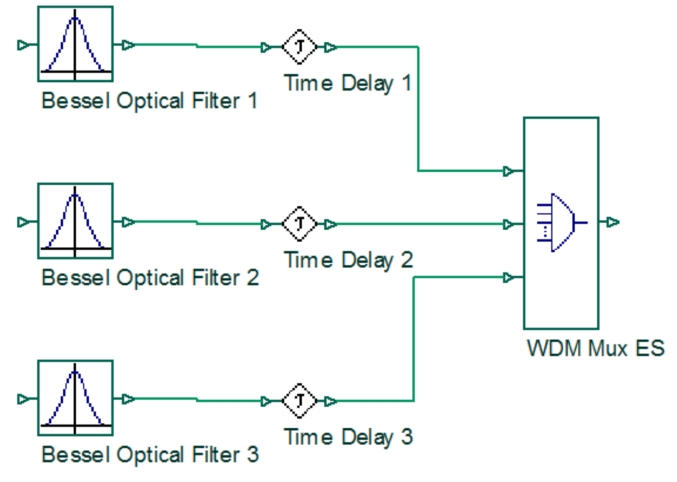

(b)

Figure 2. 2D-MD SAC-OCDMA encoder (a) and decoder (b) for user 1.

Due to the inclusion of 2D-MD code in the ZCC code families, the detection technique that can be applied is SDD which is characterized by a simple structure where it is enough to filter a single clean wavelength to obtain the desired data [26]. On the other hand, there are two utilized functions that show the importance of code properties, which are auto-correlation and cross-correlation. The algorithm used in MAI cancellation which also matches with SDD technique [14] can be expressed as follows:

$$
\mathcal{R}(f, g)=\sum_{i=1}^{M} \sum_{j=1}^{N} a_{i, j}^{(0)} a_{i j}(g, h)= \begin{cases}w_{1} \cdot w_{2} \text { for } & f=0 \cap g=0 \\ 0 & \text { otherwise }\end{cases}
$$

We note that when two codes in both sides (transmitter and receiver) are matched, this gives auto-correlation value whereas the opposition gives cross-correlation value. Moreover, there is a relationship between MAI, auto-correlation and cross correlation: as long as auto-correlation increases, cross correlation decreases leading to cancel MAI with higher value [27].

\section{SAC-OCDMA System Performance Analysis}

In order to study the performance analysis of 2D-MD SAC-OCDMA system in LRPON context, we present in this section the SNR, BER and Q-factor expressions. SNR is described as function of detected current at the photo-detector receiver divided by the current noise. It is computed as follows:

$$
\begin{gathered}
S N R=\frac{I^{2}}{I_{\text {noise }}{ }^{2}} \\
I^{2}=\left(\frac{R P_{s r} w_{1}}{M}\right)^{2}
\end{gathered}
$$

The $I_{\text {noise }}{ }^{2}$ term corresponds to the addition of the variance of the shot noise, the variance of the thermal noise, the variance of the PIIN noise and the variance of the amplifier noise given as follows:

$$
I_{\text {noise }}^{2}=I_{\text {shot }}^{2}+I_{\text {thermal }}{ }^{2}+I_{\text {PIIN }}{ }^{2}+I_{\text {amp }}{ }^{2}
$$

The variance of the shot noise and the variance of the thermal noise are given in Equations (7) and (8), respectively.

$$
I_{s h o t}^{2}=e B \frac{R P_{s r} w_{1}}{M}
$$




$$
I_{\text {thermal }}^{2}=\frac{4 K_{b} T_{n} B}{R_{l}}
$$

By checking the 2D-MD codes generated in Table 2, we have referred the overlapped chip, shown in red color. Moreover, it is known that MAI is overall generated when two ones at least have the same phase. As a result, this accompanies PIIN at receiver level. To support the above mentioned result, a lot of works have been considered PIIN effect in 2D-OCDMA system [13,14]. The PIIN variance can be calculated as follows [14]:

$$
\begin{aligned}
I_{P I I N}^{2} & =B I^{2} \tau_{c}=B I^{2} \frac{\int_{0}^{\infty} r_{0}^{2}(v) d v}{\left(\int_{0}^{\infty} r_{0}(v) d v\right)^{2}}=B R^{2} \int_{0}^{\infty} r_{0}^{2}(v) d v \\
& =B R^{2} \int_{0}^{\infty}\left[\frac{P_{s r}}{K_{2} \Delta v} \sum_{k=1}^{K} d_{k} \mathcal{R}^{(0)}(i, j) \prod(v, i)\right]^{2} d v
\end{aligned}
$$

where

$$
\begin{gathered}
\Pi(v, i)=\left\{u\left[v-v_{0}-\frac{\Delta v}{2 M}(-M+2 i)\right]-\left[v-v_{0}-u \frac{\Delta v}{2 M}(-M+2 i+2)\right]\right\}=u\left[\frac{\Delta v}{M}\right] \\
I_{P I I N}^{2}=\frac{B R^{2} P_{s r}^{2}}{\left(w_{2} \Delta v\right)^{2}}\left[\left(w_{1} w_{2}\right)^{2} * \frac{\Delta v}{M}+0\right]=\frac{B R^{2} P_{s r}^{2}}{\Delta v w_{1}^{2}} w_{1}^{2}
\end{gathered}
$$

The variance of the amplifier noise is given as follows:

$$
I_{a m p}{ }^{2}=\left(4 S_{S A E}+2 h v\right) B
$$

where $S_{S A E}=n_{s p} h v(G-1)$ is defined as the spectral density of the amplified spontaneous emission of the EFDA amplifier [28]. Likewise, $v$ is the optical frequency, $G$ is the gain of the amplifier, $h$ is Planck's constant and $n_{s p}$ is referred to as the spontaneous emission factor.

$$
S N R=\frac{\left(\frac{R P_{s r} w_{1}}{M}\right)^{2}}{e B \frac{R P_{s r} w_{1}}{M}+\frac{\left(R P_{s r}\right)^{2} B w_{1}^{2}}{\Delta v M}+\frac{4 K_{b} T_{n} B}{R_{l}}+\left(4 S_{S A E}+2 h v\right) B}
$$

where $B, R, K b, T n, R L, P_{s r}$ and $\Delta v$ are the PIN bandwidth, PIN Responsivity, Boltzmann constant, PIN temperature, load charge resistance, laser optical power and wavelength bandwidth.

The BER is described as function of SNR as follows:

$$
B E R=\frac{\operatorname{erfc}\left(\sqrt{\frac{S N R}{8}}\right)}{2}
$$

Q-factor is described as function of BER as follows [29]:

$$
Q_{d B}=20 \log _{10}\left(\sqrt{2} e r f c^{-1}(2 B E R)\right)
$$

The effect of the nonlinear impairment to the SAC-OCDMA system performance is studied through the generalized nonlinear Schrödinger (GNLS) equation, defined as follows [30]:

$$
\frac{\partial A}{\partial z}+\beta_{1} \frac{\partial A}{\partial t}-j \frac{\beta_{2}}{2} \frac{\partial^{2} A}{\partial^{2} t}-\frac{\beta_{3}}{6} \frac{\partial^{3} A}{\partial^{3} t}+\frac{\alpha}{2} A=-j \gamma|A|^{2} A
$$

where $z$ is the propagation distance and $A$ is the scalar version of the optical field.

In Equation (14), the linear terms are the attenuation coefficient $\alpha$, the group delay term $\beta_{1}$, the second order dispersion coefficient $\beta_{2}$ and the third order dispersion coefficient $\beta_{3}$ whereas $\gamma$ is the nonlinear coefficient (i.e., Kerr). 
The nonlinear coefficient is defined as [30]:

$$
\gamma=\frac{2 \pi n_{2}}{\lambda A_{e f f}}
$$

where $n_{2}$ and $A_{\text {eff }}$ are defined as the nonlinear index fiber $\left(2.6 \times 10^{-20} \mathrm{~m}^{2} / \mathrm{W}\right)$ and the fiber mode effective area, respectively. The effective area is defined as a quantitative measure of the area which a fiber mode effectively covers in the transverse dimensions. The fiber mode effective area is mathematically described as [31]:

$$
A_{e f f}=\frac{\left(\iint|A(x, y)|^{2} d x d y\right)^{2}}{\iint|A(x, y)|^{4} d x d y}
$$

where $A(x, y)$ is defined as the distribution of the optical field on $x$ and $y$ axis.

The group delay term $\beta_{1}$ is defined as follows:

$$
\beta_{1}=\frac{1}{v_{g}}=\frac{n_{g}}{c}
$$

where $v_{g}$ and $n_{g}$ defined as group velocity and group index.

In the wavelength domain, the GVD parameters $D$ and $S$ are defined as follows:

$$
D=\frac{\partial \beta_{1}}{\partial \lambda} \text { and } S=\frac{\partial D}{\partial \lambda}
$$

However, in the frequency domain, the GVD parameters $\beta_{2}$ and $\beta_{3}$ are defined as follows:

$$
\beta_{2}=\frac{\partial \beta_{1}}{\partial \omega} \text { and } \beta_{3}=\frac{\partial \beta_{2}}{\partial w}
$$

where $w$ is defined as the angular frequency of the optical field.

\section{Results and Discussion}

Table 4 exhibits the simulation parameters deployed for the numerical simulation results of the Q-Factor calculation performed using a computer simulator tool, in particular for continuous wave (CW) Laser Array transmitter, Standard SMF (SSMF) specification G.652 [32] and PIN specification [33], respectively.

Table 4. Numerical simulations parameters.

\begin{tabular}{ccc}
\hline Symbol & Description & Value \\
\hline$\lambda$ & Wavelength & $1550 \mathrm{~nm}$ \\
$\mathrm{P}_{\mathrm{T}}$ & CW laser optical power & $-5 \mathrm{dBm}$ \\
$\Delta \lambda$ & DFB spectral width & $0.5 \mathrm{~nm}$ \\
$L$ & SMF length & $(50-600) \mathrm{km}$ \\
$A$ & SMF attenuation loss & $0.2 \mathrm{~dB} / \mathrm{km}$ \\
$\mathrm{D}_{\mathrm{c}}$ & SMF Chromatic dispersion coefficient & $16 \mathrm{ps} / \mathrm{nm} \cdot \mathrm{km})$ \\
$\mathrm{R}$ & PIN Responsivity & $1 \mathrm{~A} / \mathrm{W}$ \\
$\mathrm{B}$ & PIN bandwidth & $20 \mathrm{GHz}$ \\
$\mathrm{I}_{\mathrm{dc}}$ & PIN dark current & $10 \mathrm{nA}$ \\
$\mathrm{Er}$ & MZM extinction ratio & $20 \mathrm{~dB}$ \\
$K$ & Simultaneous users & 4 \\
$\mathrm{D}$ & Bit rate & $(10-100) \mathrm{Gb} / \mathrm{s}$ \\
$\Delta \lambda_{i}$ & WDM multiplexer/demultiplexer & $0.8 \mathrm{~nm}$ \\
\hline
\end{tabular}




\subsection{First Scenario: Without Considering MAI Effects}

In order to focus on the other system limitations (i.e., nonlinear effects, increasing of bit rate and increasing of fiber length), we consider the system performance with a single user and without considering the MAI effects.

\subsubsection{Q-Factor versus Bit Rate}

Figure 3 presents the SAC-OCDMA system performance in terms of Q-factor versus bit rate (10-100) Gb/s, while taking into account the case of GVD in wavelength domain (i.e., $\beta_{1}$ only) and GVD in frequency domain (i.e., $\beta 2$ and $\beta 3$ ). The total distance simulated is $250 \mathrm{~km}$ of SMF. As shown in Figure 3, the degradation in system performance is observed at bit rates above $55 \mathrm{~Gb} / \mathrm{s}$ per network user corresponding to Q-factor below the $\mathrm{Q}$ limit (i.e., $\mathrm{Q}$ limit equal to $15.5 \mathrm{~dB}$ required to obtain a BER less than $10^{-9}$ ), when the GVD in wavelength domain is considered (i.e., $\mathrm{D}=16 \mathrm{ps} / \mathrm{nm} / \mathrm{km}$ and $\mathrm{S}=0.08 \mathrm{ps} / \mathrm{nm}^{2} / \mathrm{km}$ ). We also note that when the second and the third order dispersion are considered in the frequency domain (i.e., $\beta 2=-20 \mathrm{ps}^{2} / \mathrm{km}$ and $\beta 3=0 \mathrm{ps}^{3} / \mathrm{km}$, respectively), a degradation in system performance of $1 \mathrm{~dB}, 5.9 \mathrm{~dB}$ and $10.6 \mathrm{~dB}$ are observed at $30 \mathrm{~Gb} / \mathrm{s}, 40 \mathrm{~Gb} / \mathrm{s}$ and $50 \mathrm{~Gb} / \mathrm{s}$, respectively. Finally, the Q-factor limit of $15.5 \mathrm{~dB}$ is maintained at a total bit rate of $55 \mathrm{~Gb} / \mathrm{s}$, when the effects of GVD is manifested in the wavelength domain. Furthermore, when the GVD is simulated with frequency domain parameters $(\beta 2, \beta 3)$, the system performance at a bit rate of $40 \mathrm{~Gb} / \mathrm{s}$ results, to a certain extent, in a Q-factor within the vicinity of the Q-factor limit of $15.5 \mathrm{~dB}$. The results in Figure 3 illustrate the potential of utilizing Forward Error Correction (FEC) to mitigate the performance penalty due to the frequency domain parameters $(\beta 2, \beta 3)$. For example, a hard decision FEC limit at a BER threshold of $3.8 \times 10^{-3}$ corresponding to a $\mathrm{Q}$ limit of $8.5 \mathrm{~dB}$ [34] can be applied with a $7 \%$ overhead. As such, the results in Figure 3, can be used in principle to estimate the potential gain from applying FEC encoding/decoding. By way of an example, a bit rate of $42.8 \mathrm{~Gb} / \mathrm{s}$ which accounts for the $7 \%$ overhead and the target data bit rate of $40 \mathrm{~Gb} / \mathrm{s}$ maintains a Q-factor above the FEC limit of $8.5 \mathrm{~dB}$, resulting in error free transmission for the target data bit rate of $40 \mathrm{~Gb} / \mathrm{s}$.

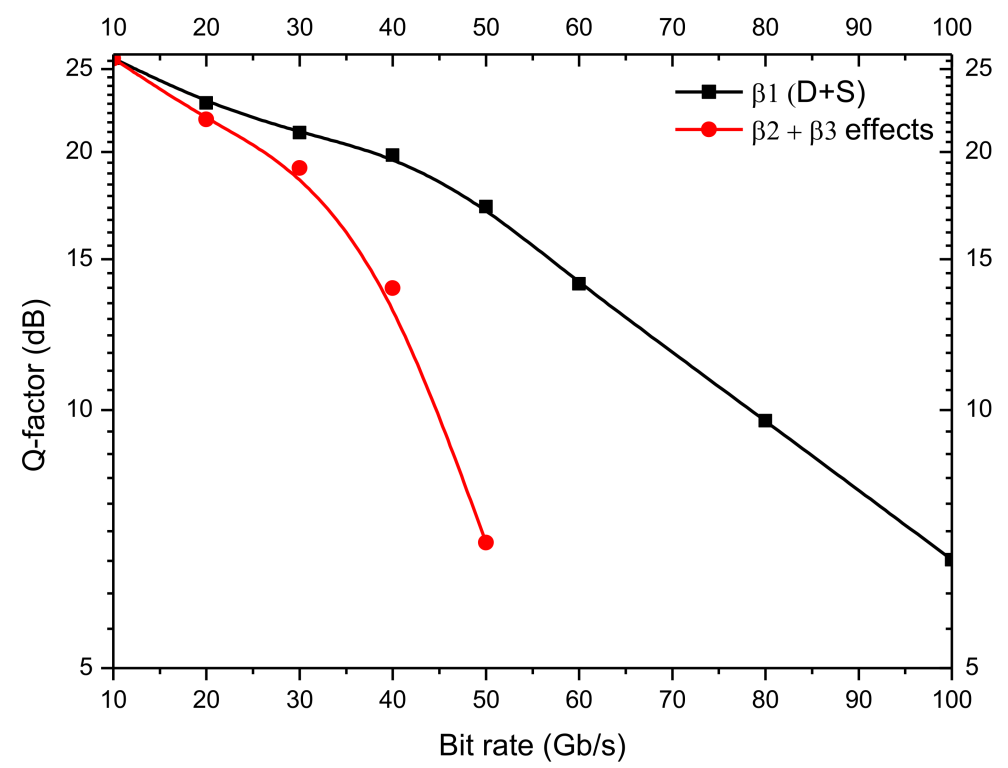

Figure 3. SAC-OCDMA system performance versus bit rate.

\subsubsection{Q-Factor versus Effective Area}

Figure 4 presents the SAC-OCDMA system performance versus the effective area (Aeff) in the range of (13-93) $\mu \mathrm{m}^{2}$ while increasing the bit rate and taking into account the second order dispersion ( $\beta 2)$, the third order dispersion $(\beta 3)$ and the nonlinear coefficient 
$(\gamma)$. The optical launch power was fixed to $-3.4 \mathrm{dBm}$ per user to facilitate isolating the effect of changing the effective area of the optical fiber. The numerical simulations can tolerate a maximum nonlinear phase shift of $10 \mathrm{mrad}$ prior to updating the step-size of the fiber propagator.

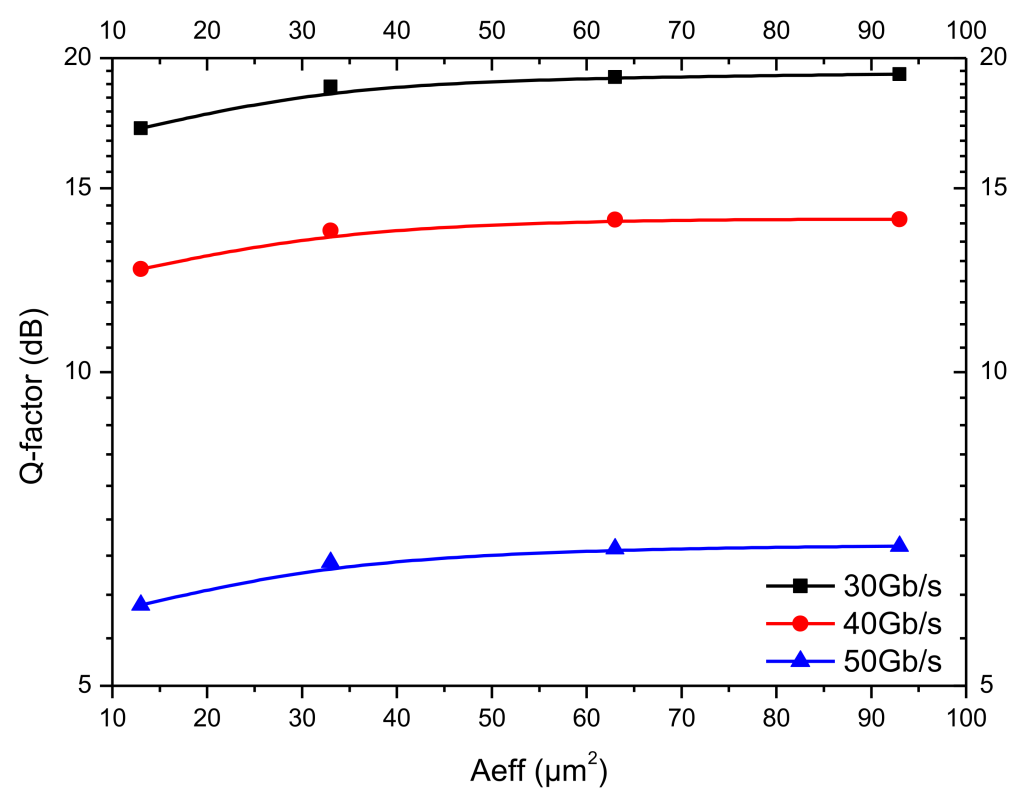

Figure 4. SAC-OCDMA system performance versus effective area.

As depicted in Figure 4, at $30 \mathrm{~Gb} / \mathrm{s}$ per user, the SAC-OCDMA system based on 2D-MD codes can tolerate the effects of second and third order dispersion and results in a Q-factor above the Q-limit with an average of $7 \mathrm{~dB}$ margin across all values of Aeff. However, above $40 \mathrm{~Gb} / \mathrm{s}$ the second and third order dispersion become dominant leading to a degradation of the system performance while increasing the effective area. From Equation (16), the effective area of the SMF is inversely proportional to the nonlinear coefficient. Since the effective area decreases the nonlinear effect increases leading to the degradation of the system performance. When the effective area is considered and through increasing the bit rate from $30 \mathrm{~Gb} / \mathrm{s}$ to $40 \mathrm{~Gb} / \mathrm{s}$, a degradation of the system performance of $5.3 \mathrm{~dB}, 5.2 \mathrm{~dB}$ and $5.1 \mathrm{~dB}$ is observed in terms of Q-factor at $93 \mu \mathrm{m}^{2}, 63 \mu \mathrm{m}^{2}$ and $33 \mu \mathrm{m}^{2}$, respectively. In addition, while increasing the bit rate from $40 \mathrm{~Gb} / \mathrm{s}$ to $50 \mathrm{~Gb} / \mathrm{s}$ a degradation of system performance of $7.2 \mathrm{~dB}, 7.2 \mathrm{~dB}$ and $7.1 \mathrm{~dB}$ is observed at $93 \mu \mathrm{m}^{2}$, $63 \mu \mathrm{m}^{2}$ and $33 \mu \mathrm{m}^{2}$, respectively. As a result, the nonlinear effects with a high bit rate above $40 \mathrm{~Gb} / \mathrm{s}$ led to a marginal performance degradation in the proposed SAC-OCDMA system. Therefore, the nonlinear effects seem to have insignificant effects on the Q-factor values unless the bit rate is relatively low (i.e., $30 \mathrm{~Gb} / \mathrm{s}$ ). This in fact can be explained in terms of the interplay between fiber dispersion and nonlinearity. At higher bit rates, pulse durations are shorter and thus experience the onset of fiber dispersion more rapidly resulting in pulse broadening and overlapping in time. Consequently, the induced nonlinear phase noise is largest when the signal is slow to evolve during propagation in dispersion managed systems. Furthermore, the results in Figure 4, show that the use of Large Effective Area Fibers (LEAF) in dispersion managed systems offer marginal improvement in system performance. It is worth noting that our computer simulator tool utilizes the so called "total field model", which merges all channels into a single optical field and propagated it through a single scaler version of Equation (14). Inherently, the effects of four wave mixing (FWM) is also modelled through this approach. The effect of FWM is reduced with the presence of chromatic dispersion as the propagating user channels become decoherent with reduced phase matching. As FWM does not depend on bit rate, the results in Figure 4 illustrate that SPM is indeed the predominant nonlinear distortion. 


\subsubsection{Q-Factor versus Fiber Length}

Figure 5 shows a comparison between the system performance with nonlinear effects (i.e., SPM and SRS) and without nonlinear effects (i.e., without NLE) versus the distance (i.e., fiber length) at a bit rate equal to $10 \mathrm{~Gb} / \mathrm{s}$ per user and an effective area equal to $23 \mu \mathrm{m}^{2}$. One can see that the system limitation in terms of distance at the Q-limit is observed around $600 \mathrm{~km}$ and $480 \mathrm{~km}$ with linear and with nonlinear effects, respectively. In addition, when nonlinear effects are considered a degradation of system performance of $1.6 \mathrm{~dB}, 2.7 \mathrm{~dB}$ and $11.4 \mathrm{~dB}$ is observed at $300 \mathrm{~km}, 400 \mathrm{~km}$ and $500 \mathrm{~km}$, respectively. In fact, SPM is related to the degradation of system performance due to the optical shift phase during the propagation through the core of the fiber [35]. The optical launch power was optimized for each transmission distance. The effect of SPM can be reduced through allowing a certain amount of residual dispersion in the design of the dispersion map.

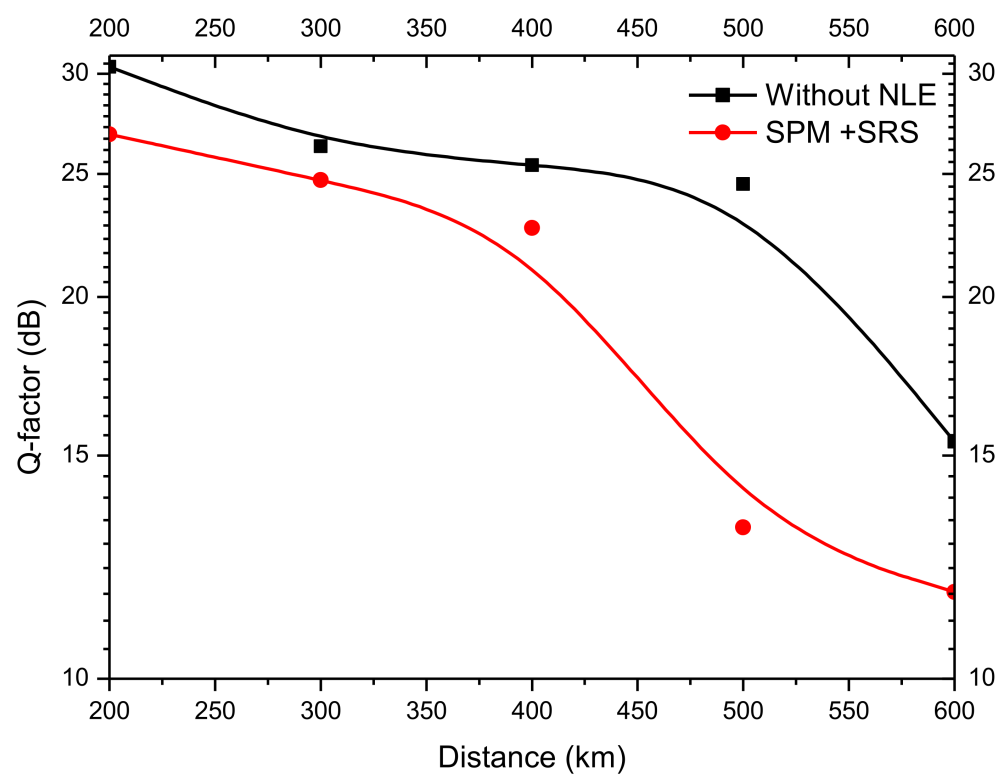

Figure 5. SAC-OCDMA system performance versus fiber length.

\subsection{Second Scenario: With Considering MAI Effect}

In this section, we consider all the effects including the MAI on SAC-OCDMA system performance. Figure 6, presents the system setup for four users. This system is composed of a CW laser array used to generate the three wavelengths required by the SAC-OCDMA encoder to produce the user signature for each network subscriber. Furthermore, user bits are generated by a pseudo-random bit sequence (PRBS) with a sequence length of $2^{14}-1$ followed by an NRZ block to produce a line code. Then, a MZM external modulator is used to modulate the electrical user signal using the optical carrier generated by the CW laser. A SAC-OCDMA encoder is employed to multiply the generated ' 1 ' user bit by the 2D-MD signature. Then, all user contributions are combined in one composite signal transferred into the optical channel. At the reception side, a SAC-OCDMA decoder is employed to extract the desired user signal from the received signal. Then, a photo-detector PIN is used to convert the optical desired signal into the electrical one. Furthermore, a Bessel filter, with a cutoff frequency equal to 0.75 muliplied by the bit rate, is employed to limit the signal into the desired frequency band. Finally, a BER analyzer is used to measure the quality of the received user signal in terms of Q-factor and eye diagram. According to Figure 4 (i.e., Q-factor versus effective area), we have to choose an aggregate bit rate less than $30 \mathrm{~Gb} / \mathrm{s}$ to obtain a Q-factor higher than $15.5 \mathrm{~dB}$. Indeed, we select a bit rate equal to $5 \mathrm{~Gb} / \mathrm{s}$ per user to fulfill the high-quality transmission and to respect the user requirement for access network in terms of QoS. 


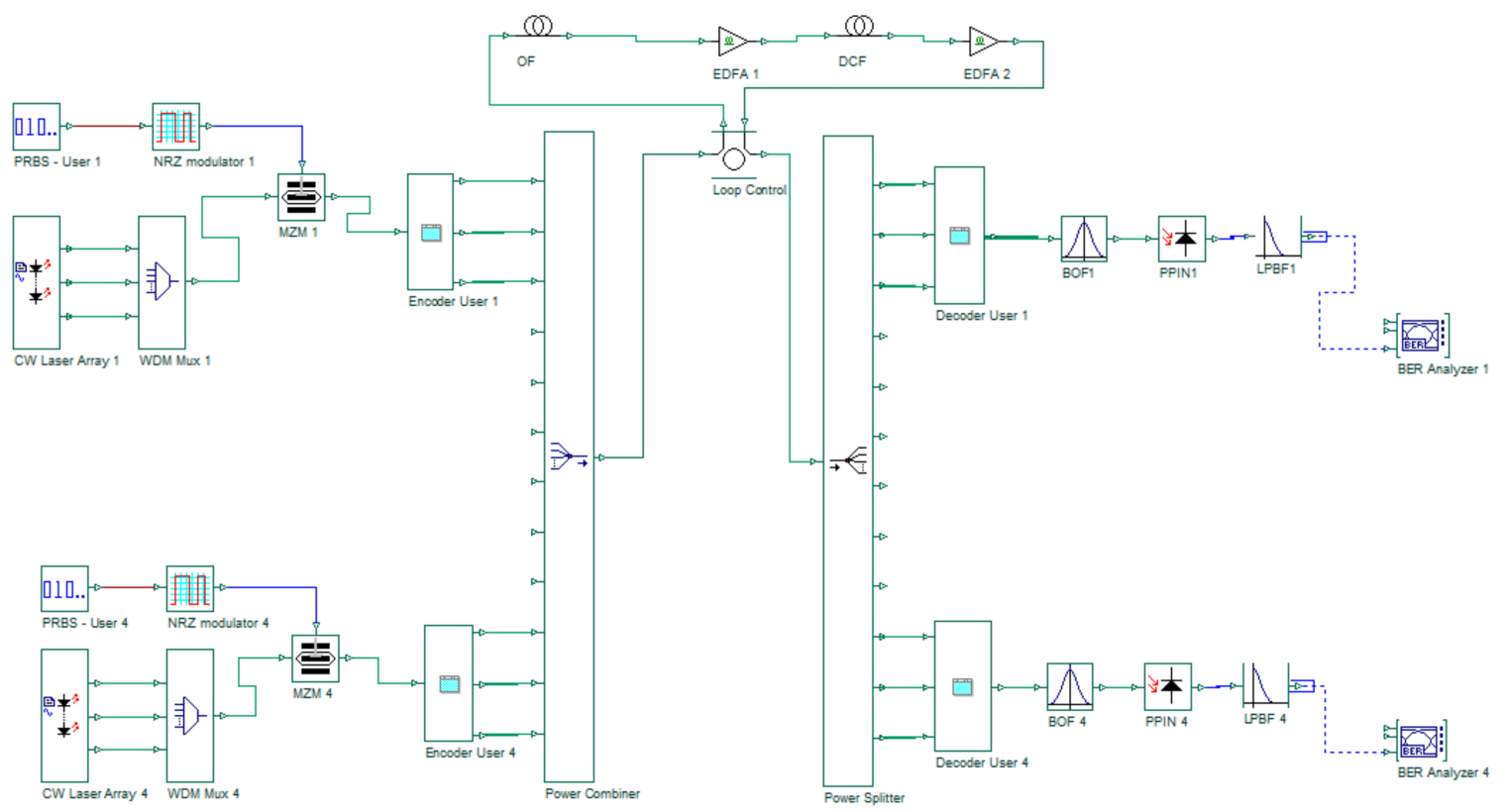

Figure 6. Simulation setup of 2D-MD SAC-OCDMA system supporting four users (MZM: Mach-Zehnder Modulator, OF: Optical Fiber, DCF: Dispersion Compensating Fiber, EDFA: Erbium Doped Fiber Amplifier, BOF: Bessel Optical Filter, PPIN: Photodiode PIN, LPBF: Low Pass Bessel Filter).

Figure 7 shows the received electrical eye diagram for the different simultaneous users at $5 \mathrm{~Gb} / \mathrm{s}$ per user and over $50 \mathrm{~km}$ of fiber transmission, while considering the optical coherent source noise, the linear effects (fiber loss, GVD, DGD), the nonlinear effects (SPM, SRS and $\gamma$ ) and the photodetector noise (i.e., thermal and shot noises). According to Figure 7, the system can accommodate four users leading to a total aggregate bit rate of $20 \mathrm{~Gb} / \mathrm{s}$ with an open eye diagram. Additionally, the open eye diagram of the four simultaneous users indicates a high transmission quality at an aggregate bit rate of $20 \mathrm{~Gb} / \mathrm{s}$.

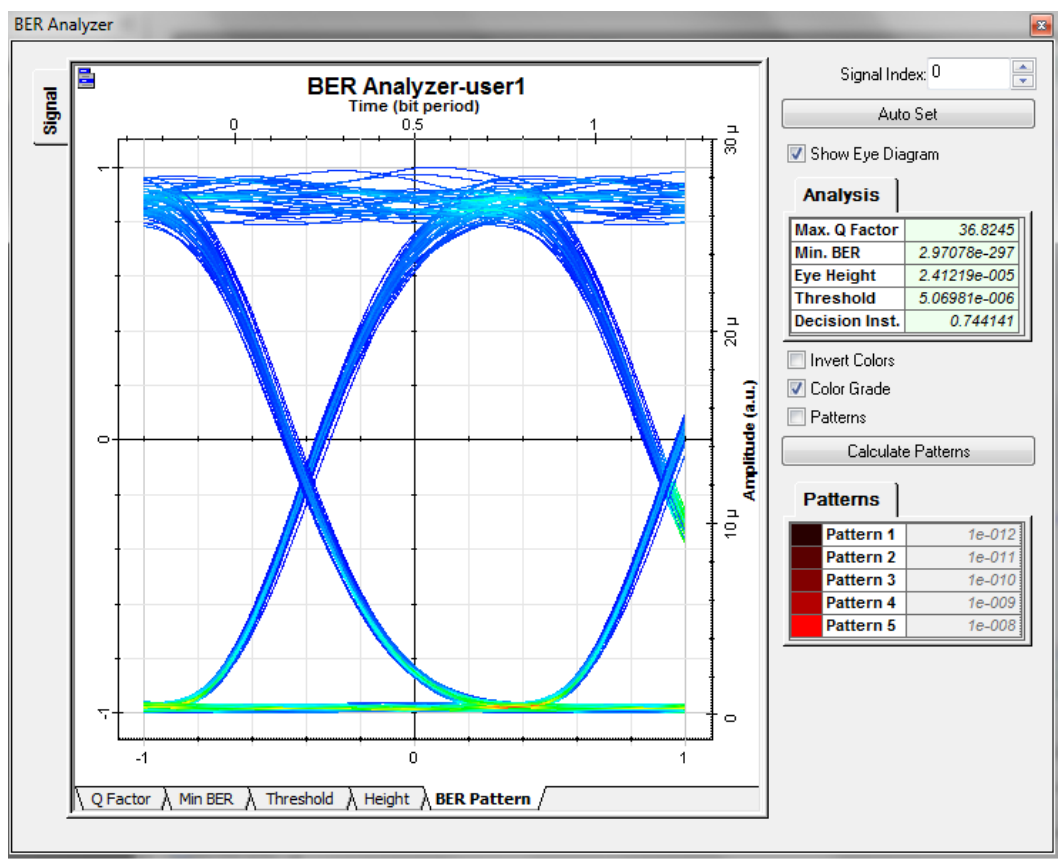

(a)

Figure 7. Cont. 


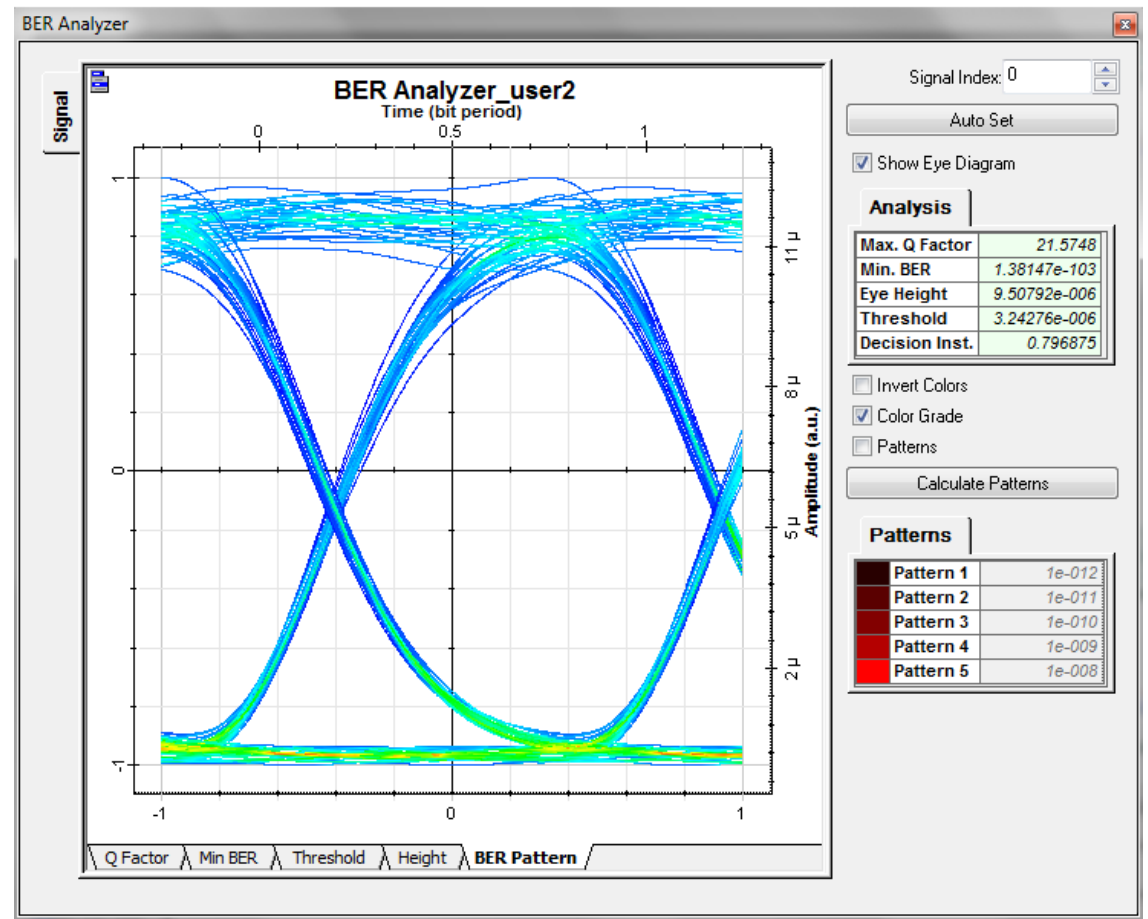

(b)

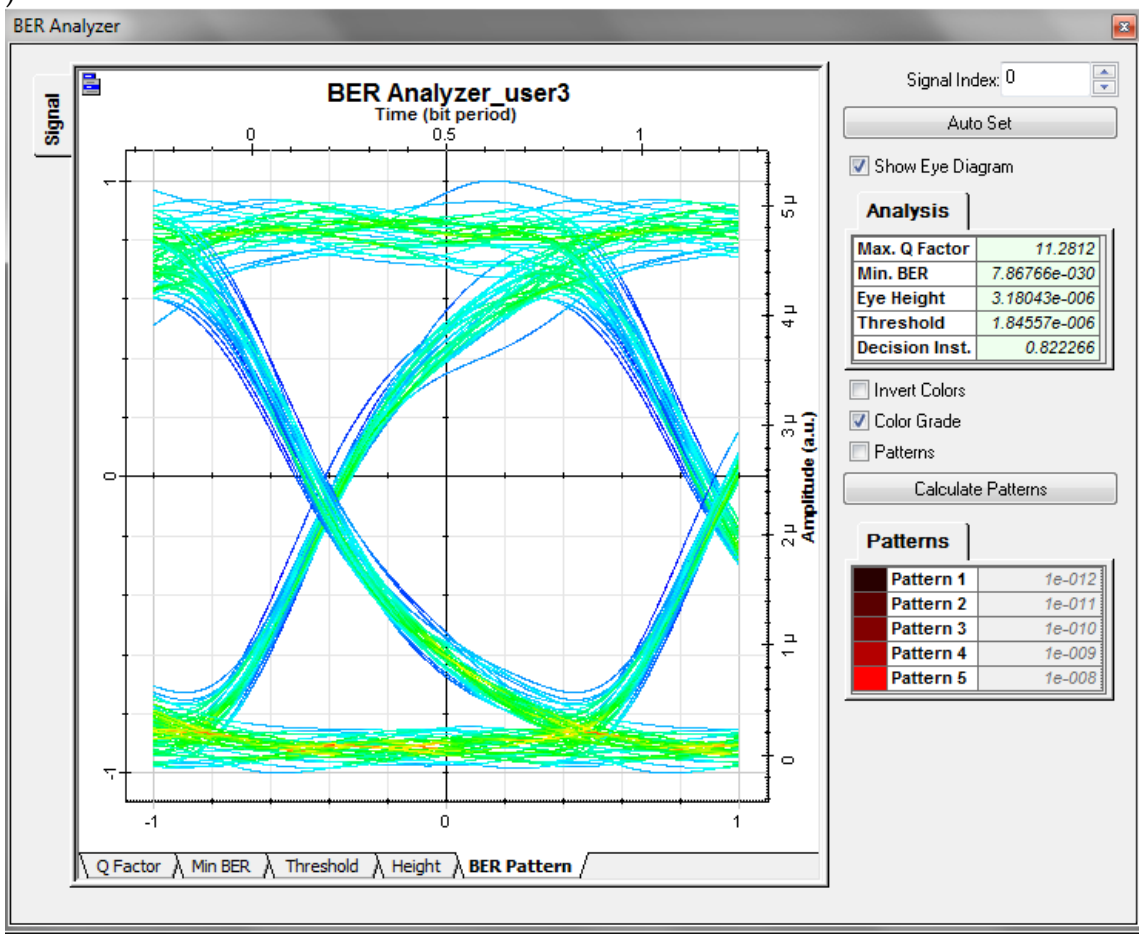

(c)

Figure 7. Cont. 


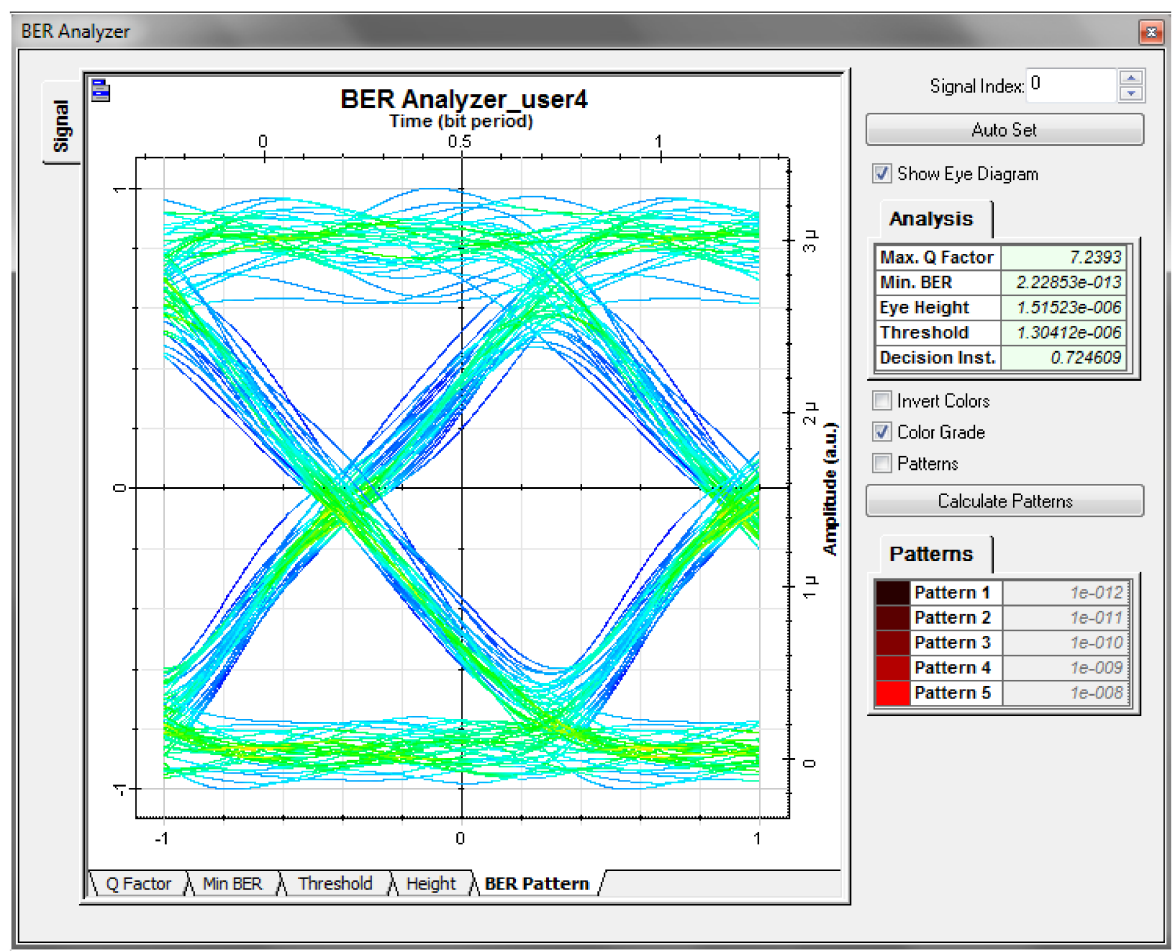

(d)

Figure 7. Received electrical eye diagrams: (a) for user 1; (b) for user 2; (c) for user 3; (d) for user 4. The bit rate is $5 \mathrm{~Gb} / \mathrm{s}$ per user and the transmission is over $50 \mathrm{~km}$ of SMF.

Furthermore, Table 5 illustrates a Q-factor greater than $15.5 \mathrm{~dB}$ for all users considering linear and nonlinear effects for two effective area values (Aeff $=93 \mu \mathrm{m}^{2}$ and $23 \mu \mathrm{m}^{2}$ ). In this simulation, the optical launch power was fixed to $-3.4 \mathrm{dBm}$ per user.

Table 5. Q-factor $(\mathrm{dB})$ for the four users.

\begin{tabular}{|c|c|c|c|}
\hline Linear Effects & $\begin{array}{c}\text { Nonlinear Effects } \\
\left(A_{\text {eff }}=93 \mu \mathrm{m}^{2}\right)\end{array}$ & $\begin{array}{c}\text { Nonlinear Effects } \\
\left(\mathrm{A}_{\text {eff }}=23 \mu \mathrm{m}^{2}\right)\end{array}$ & Linear Effects \\
\hline User 1 & 31.3 & 29.9 & 31.7 \\
\hline User 2 & 26.7 & 26.5 & 27.6 \\
\hline User 3 & 21.1 & 20.8 & 21.4 \\
\hline User 4 & 17.2 & 16.9 & 17.3 \\
\hline
\end{tabular}

However, a degradation of the Q-factor is observed while increasing the number of users. Indeed, this degradation is due to the fact that increasing the number of users leads to the increasing of MAI and as a consequence the system performance decreases significantly. For one user (i.e., example user 1) the difference in Q-factor when nonlinear effect is counted (column 3 compared to column 4 ) is equal to $(31.7-29.9)=1.8 \mathrm{~dB}$. So, in this scenario the nonlinear effect is a dominant factor compared to MAI. On the other hand, above one user (i.e., example user 2, user 3 and user 4 are considered) the difference in Q-factor when nonlinear effects is counted becomes limited and less than $1 \mathrm{~dB}$. So, in this case MAI is more dominant compared to the nonlinear effects.

In addition, when the effective area decreases from $93 \mu \mathrm{m}^{2}$ to $23 \mu \mathrm{m}^{2}$, the nonlinear effects increase proportionally. As a conclusion, the raising of the bit rate and the increasing of the number of users (i.e., increasing the MAI) and the nonlinear effects (by decreasing the fiber mode effective area) are the most important causes of 2D-MD SAC-OCDMA system performance degradation. 
To show the maximum number of allowed users permitted by the system as function of the bit rate, Figure 8 represents the variation of the bit rate per user versus the number of users. According to Figure 8, the maximum number of the allowed users is equal to 16,8 and 4 at a BER value equal to $10^{-9}$ and operating at $1.25 \mathrm{~Gb} / \mathrm{s}, 2.5 \mathrm{~Gb} / \mathrm{s}$ and $5 \mathrm{~Gb} / \mathrm{s}$ per user, respectively. Furthermore, a trade-off is observed between the raising of the bit rate and the decreasing of the number of the allowed users.

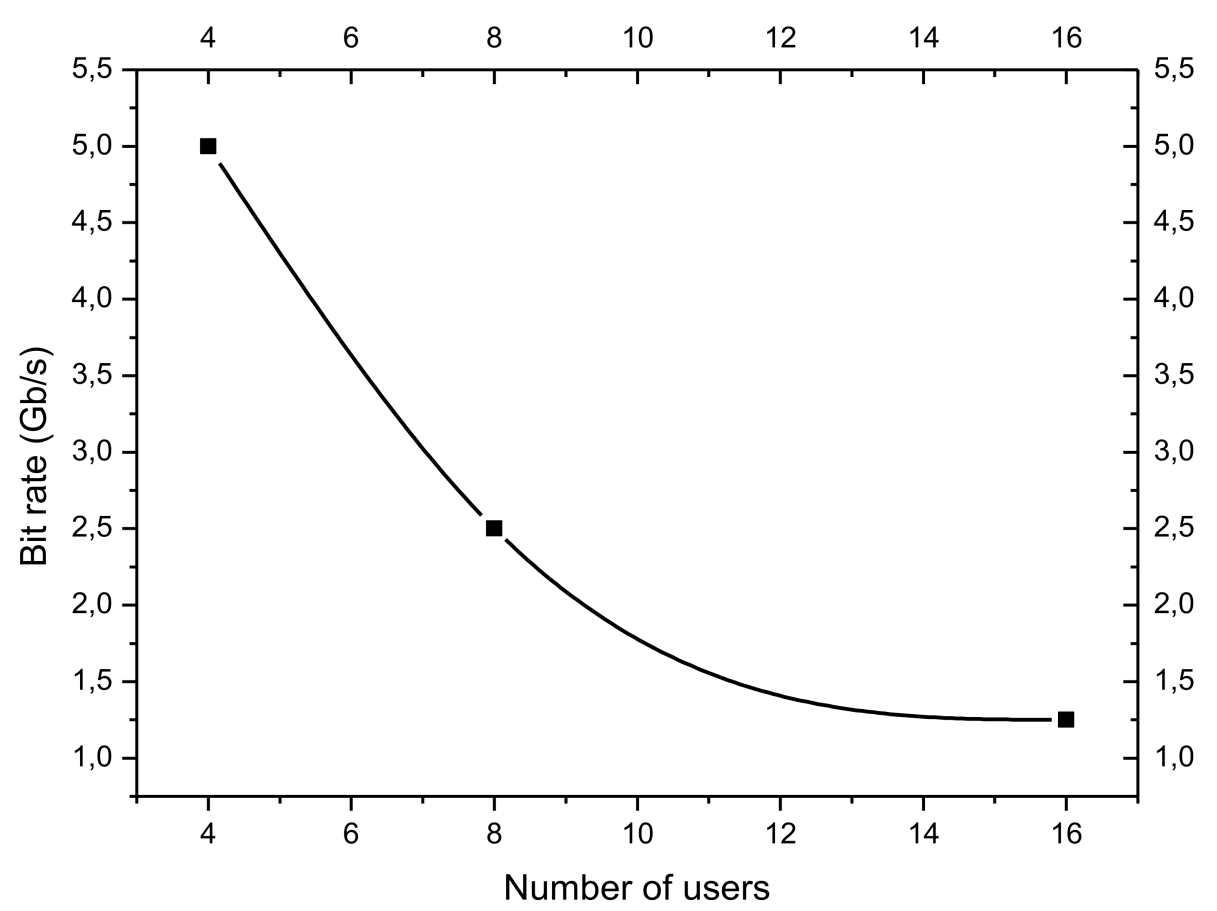

Figure 8. Bit rate versus the number of simultaneous users.

In order to show the add value of our proposed system compared to the literature, Table 6 makes a fair comparison of the different SAC-OCDMA systems in PON configuration in terms of coding scheme, cardinality (i.e., number of users supported in the system setup), performance measured metrics, supported bit rate per user and transmission reach.

Table 6. Comparison of SAC-OCDMA systems based on coherent source.

\begin{tabular}{|c|c|c|c|c|}
\hline System & $\begin{array}{l}\text { Coding } \\
\text { Scheme }\end{array}$ & $\begin{array}{l}\text { Cardinality for } \\
\text { System Setup }\end{array}$ & $\begin{array}{c}\text { Performance } \\
\text { Measured Metrics }\end{array}$ & $\begin{array}{c}\text { Aggregate Bit } \\
\text { Rate }\end{array}$ \\
\hline 1D-RD with multi-laser source [18] & 1D-RD & 2 & $\mathrm{BER}<10^{-9}$ & $10 \mathrm{~Gb} / \mathrm{s}$ \\
\hline 1D-BIBD with muli-laser source [19] & 1D-BIBD & 12 & $\mathrm{BER} \leq 10^{-12}$ & $1.25 \mathrm{~Gb} / \mathrm{s}$ \\
\hline SAC-OCDMA with 1D-MD codes [20] & 1D-MD & 5 & $\mathrm{BER}<10^{-9}$ & $10 \mathrm{~Gb} / \mathrm{s}$ \\
\hline 1D-MD with muli-array laser [21] & 1D-MD & 7 & $\mathrm{BER}<10^{-9}$ & $12 \mathrm{~Gb} / \mathrm{s}$ \\
\hline 2D-MD SAC-OCDMA for LR-PON ${ }^{1}$ & 2D-MD & $4 / 8 / 16$ & Q-factor $\geq 15.5 \mathrm{~dB}$ & $20 \mathrm{~Gb} / \mathrm{s}$ \\
\hline
\end{tabular}

${ }^{1}$ Our proposed system.

As shown from Table 6, various OCDMA coding schemes are proposed by researchers for SAC-OCDMA based on coherent sources such as 1D random diagonal (1D-RD) codes [18], 1D-BIBD codes [19] and 1D-MD codes [20,21].

As depicted in Table 6, the proposed 2D-MD SAC-OCDMA system for LR-PON outperforms alternate proposals in literature in terms of the aggregate bit rate (i.e., $20 \mathrm{~Gb} / \mathrm{s}$ ) and transmission reach up to $50 \mathrm{~km}$ over SMF link, while maintaining a high-performance measured metrics via a $\mathrm{Q}-$ factor greater than $15.5 \mathrm{~dB}$. As a conclusion, our proposed 2D-MD SAC-OCDMA system is well suited for LR-PON and can be a potential candidate for granting access network with high system performance and high security. In addition, it is known 
that SAC-OCDMA system provides the integrity security component inherited from the OCDMA features. In fact, without knowing the 2D-MD coding scheme it is impossible for any eavesdropper to decode the user's signal and make any unauthorized change.

\section{Conclusions}

In this paper, a new architecture is proposed for SAC-OCDMA system by employing 2D-MD codes and laser optical source for LR-PON context. The system performance of our proposal is addressed by numerical investigation as function of MAI, bit rate, SMF length and fiber mode effective area. Moreover, optical coherent source noise, channel nonlinearity, shot noise and thermal noise of the PIN photodetector are considered for system performance analysis. In the case of a single user (i.e., without considering MAI), we observe that a Q-limit is achieved for bit rates around $55 \mathrm{~Gb} / \mathrm{s}$ and $40 \mathrm{~Gb} / \mathrm{s}$ when the first and the second (same results for the third) order dispersion are taken into consideration, respectively. Furthermore, the proposed system provides a $30 \mathrm{~Gb} / \mathrm{s}$ bit rate with performance above the Q-limit, while increasing the effect of fiber nonlinearity. We also demonstrated that our new proposed architecture extends the fiber length up to $600 \mathrm{~km}$ and $480 \mathrm{~km}$, while considering linear and nonlinear effects, respectively. In the case of considering the MAI effects, an aggregate bit rate of $20 \mathrm{~Gb} / \mathrm{s}$ for 4,8 and 16 simultaneous users are achieved with a Q-factor greater than $15.5 \mathrm{~dB}$ while considering optical laser source noise, linear effects, nonlinear effects and photo-detector noise. Likewise, we show, through extensive simulations, that our proposal outperforms alternate solutions in literature by offering $20 \mathrm{~Gb} / \mathrm{s}$ as an aggregate bit rate and a transmission reach up to $50 \mathrm{~km}$ for 4, 8 and 16 simultaneous users. As a conclusion, the proposed 2D-MD SAC-OCDMA system in LR-PON configuration can be viewed as a potential candidate for future access network by offering high level of both performance and security [36].

Author Contributions: Conceptualization, H.M. and F.B.; methodology, A.S.K., software, H.M.; validation, F.B., A.S.K. and A.C.; formal analysis, A.C.; investigation, A.B.; resources, F.B.; data curation, H.M.; writing — original draft preparation, H.M.; writing—review and editing, H.M.; visualization, A.B.; supervision, A.S.K.; project administration, F.B.; funding acquisition, A.B. All authors have read and agreed to the published version of the manuscript.

Funding: This research received no external funding.

Institutional Review Board Statement: Not applicable.

Informed Consent Statement: Not applicable.

Conflicts of Interest: The authors declare no conflict of interest.

\section{References}

1. Kitayama, K. Optical Code Division Multiple Access: A Practical Perspective, 1st ed.; Cambridge University Press: Cambridge, UK, 2014.

2. Akhoundi, F.; Salehi, J.A.; Tashakori, A. Cellular Underwater Wireless Optical CDMA Network: Performance Analysis and Implementation Concepts. IEEE Trans. Commun. 2015, 63, 882-891. [CrossRef]

3. Mrabet, H.; Dayoub, I.; Attia, R. A comparative study of 2D-OCDMAWDM system performance in 40-Gb/s PON context. IET Optoelectron. 2017, 11, 141-147. [CrossRef]

4. Karimi, M.; Kenari, M.N. An internally coded TH/OCDMA scheme for fiber optic communication systems and its performance analysis-part II: Using frame time hopping code. IEEE Trans. Commun. 2009, 57, 50-55. [CrossRef]

5. Fathallah, H.; Rusch, L.A.; la Rochelle, S. Passive Optical Fast Frequency-Hop CDMA Communications System. IEEE J. Lightwave Technol. 1999, 17, 397-405. [CrossRef]

6. Mrabet, H.; Cherifi, A.; Raddo, T.; Dayoub, I.; Haxha, S. A Comparative Study of Asynchronous and Synchronous OCDMA Systems. IEEE Syst. J. 2020, 15, 3642-3653. [CrossRef]

7. Kwong, W.C.; Perrier, P.; Prucnal, P.R. Performance comparison of asynchronous and synchronous code division multiple access techniques for fiber-optic local area networks. IEEE Trans. Commun. 1991, 39, 1625-1634. [CrossRef]

8. Farghal, A.E.A. Performance analysis of core-multiplexed spectral amplitude coded OCDMA PON. IEEE/OSA J. Opt. Commun. Netw. 2016, 8, 666-675. [CrossRef]

9. Nawawi, N.M.; Anuar, M.S.; Junita, M.N. Cardinality improvement of Zero Cross Correlation (ZCC) code for OCDMA visible light communication system utilizing catenated-OFDM modulation scheme. Optik 2018, 170, 220-225. [CrossRef] 
10. Cherifi, A.; Yagoubi, B.; Bouazza, B.S.; Dahman, A.O. Performance analysis of optical CDMA system based on zero cross correlation (ZCC) code using OFDM modulation. Int. J. Signal Process. 2016, 1, 91-96.

11. Garadia, A.; Djebbaria, A.; Abdelmalik, T. Exact analysis of signal-to-noise ratio for SAC-OCDMA system with direct detection. Optik 2017, 145, 89-94. [CrossRef]

12. Jellali, N.; Najjar, M.; Ferchichi, M.; Janyani, V. Performance enhancement of the 3D OCDMA system by using dynamic cyclic shift and multi-diagonal codes. Photonic Netw. Commun. 2018, 37, 63-74. [CrossRef]

13. Cherifi, A.; Jellali, N.; Najjar, M.; Aljunid, S.A.; Bouazza, B.S. Development of a novel two-dimensional-SWZCC-Code for spectral/spatial optical CDMA system. Opt. Laser Technol. 2019, 109, 233-240. [CrossRef]

14. Kadhim, R.A.; Fadhil, H.A.; Aljunid, S.A.; Razalli, M.S. A new two dimensional spectral/spatial multi-diagonal code for noncoherent optical code division multiple access (OCDMA) systems. Opt. Commun. 2014, 329, 28-33. [CrossRef]

15. Sharma, T.; Chehri, A.; Fortier, P.; Yousif Ahmed, H.; Zeghid, M.; Imtiaz, W.A. Optical Code Construction of 2D Spectral/Spatial BIBD Codes for SAC-OCDMA Systems. Appl. Sci. 2021, 11, 783. [CrossRef]

16. Yousif Ahmed, H.; Zeghid, M.; Imtiaz, W.A.; Sharma, T.; Chehri, A.; Fortier, P. Two-Dimensional Permutation Vectors' (PV) Code for Optical Code Division Multiple Access Systems. Entropy 2020, 22, 576. [CrossRef] [PubMed]

17. Yang, C.C.; Huang, J.F. Two-dimensional M-matrices coding in spatial/frequency optical CDMA networks. IEEE Photonics Technol. Lett. 2003, 15, 168-170. [CrossRef]

18. Fadhil, H.A.; Aljunid, S.A.; Ahmad, R.B. Design considerations of high performance optical code division multiple access: A new spectral amplitude code based on laser and light emitting diode light source. IET Optoelectron. 2010, 4, 29-34. [CrossRef]

19. Alhassan, A.M.; Badruddin, N.; Saad, N.M.; Aljunid, S.A. Enhancing the Performance of Coherent Sources SAC OCDMA Networks via Spatial Multiplexing. J. Opt. Soc. Korea 2013, 17, 471-480. [CrossRef]

20. Abd, T.H.; Aljunid, S.A.; Fadhil, H.A.; Junita, M.N.; Saad, N.M. Modelling and simulation of a 1.6 Tb/s optical system based on multi-diagonal code and optical code-division multiple-access. Ukr. J. Phys. Opt. 2012, 13, 54-66. [CrossRef]

21. Sharma, T.; Maddila, R.K. Performance characteristics of the spectral-amplitude-coding optical CDMA system based on onedimensional optical codes and a multi-array laser. Ukr. J. Phys. Opt. 2019, 20, 81-90.

22. Moghaddasi, M.; Mamdoohi, G.; Noor, A.S.M.; Mahdi, M.A.; Anas, A.S.B. Development of SAC-OCDMA in FSO with multiwavelength laser source. Opt. Commun. 2015, 356, 282-289. [CrossRef]

23. Moghaddasi, M.; Seyedzadeh, S.; Glesk, I. DW-ZCC code based on SAC-OCDMA deploying multi-wavelength laser source for wireless optical networks. Opt. Quantum Electron. 2017, 49, 393-409. [CrossRef]

24. Amari, A.; Dobre, O.A.; Venkatesan, R.; Kumar, O.S.S.; Ciblat, P.; Jaouën, Y. A Survey on Fiber Nonlinearity Compensation for $400 \mathrm{~Gb} / \mathrm{s}$ and Beyond Optical Communication Systems. IEEE Commun. Surv. Tutor. 2017, 19, 3097-3113. [CrossRef]

25. Kaur, S.; Singh, S. Review on developments in all-optical spectral amplitude coding techniques. Opt. Eng. 2018, 57, 116102. [CrossRef]

26. Mostafa, S.; Mohamed, A.E.-N.A.; El-Samie, F.E.A.; Rashed, A.N.Z. Eradication of Multiple Access Interference Using a Modified Multi-service Code for SAC-OCDMA. Wirel. Pers. Commun. 2015, 83, 855-887. [CrossRef]

27. Cherifi, A.; Mrabet, H.; Bouazza, B.S.; Aljunid, S.A. Performance enhancement of multiple access 3D-OCDMA networks using a pascal triangle codes. Opt. Quantum Electron. 2020, 52, 131-147. [CrossRef]

28. Agrawal, G.P. Fiber-Optic Communications Systems, 5th ed.; Wiley: Hoboken, NJ, USA, 2012.

29. Mrabet, H.; Dayoub, I.; Haxha, S.; Attia, R. Performance analysis of 2D-OCDMA system in long-reach passive optical network. Opt. Laser Technol. 2019, 117, 64-72. [CrossRef]

30. Agrawal, G.P. Nonlinear Fiber Optics, 4th ed.; Academic Press: Cambridge, MA, USA, 2007.

31. Okamoto, K. Fundamental of Optical Waveguide, 2nd ed.; Academic Press: Cambridge, MA, USA, 2006.

32. Characteristics of a Single-Mode Optical Fibre and Cable; Recommendation ITU-T G.652: Geneva, Switzerland. 2016. Available online: https: / / www.itu.int/itu-t/recommendations/rec.aspx?rec=13076 (accessed on 10 September 2020).

33. Brown, G.; Creath, K.; Kogelnik, H. The Optics Encyclopedia (Basic Foundations and Practical Applications); Wiley: Hoboken, NJ, USA, 2004.

34. Tychopoulos, A.; Koufopavlou, O.; Tomkos, I. FEC in optical communications-A tutorial overview on the evolution of architectures and the future prospects of outband and inband FEC for optical communications. IEEE Circuits Devices Mag. 2006, 22, 79-86. [CrossRef]

35. Christiansen, P.L.; Sorensen, M.P.; Scott, A.C. Nonlinear Science at the Dawn of the 21st Century; Springer LNP: Berlin, Germany, 2000; Volume 542.

36. Mrabet, H. A Performance Analysis of a Hybrid OCDMA-PON Configuration Based on IM/DD Fast-OFDM Technique for Access Network. Appl. Sci. 2020, 10, 7690. [CrossRef] 